\title{
3D-KINEMATICS OF UPPER LIMB IN CHILDREN With CEREBRAl PALSY: A Clinical EXPERIENCE
}

\author{
Cimolin, V.; Galli, M.; CRivellini, M. \& Albertini, G.
}

Abstract: 3D motion analysis has turned out to be a powerful tool for a quantitative assessment of the movement, thanks to several important features: it is non invasive, it allows to repeat the examination more times within a short period of time, it provides quantitative and three-dimensional data concern kinematics, kinetics and quantitative evaluation of muscle activity. For clinical application the breakthrough of $3 D$ motion analysis can be attributed to gait analysis, or quantitative analysis of walking; other motor tasks, as upper extremities movements, are instead at an early stage, and the introduction to clinical routine seems to be a step for the future. From a clinical point of view, the analysis of upper limb motion reveled to be very important for the evaluation of non walking subjects and for that of patients that have a limited functional movement or kinematical abnormalities in upper limbs, such as hemiplegic and tetraplegic patients in Cerebral Palsy, too. This chapter describes the experience of the Posture and Motion Laboratory at the IRCCS "San Raffaele" (part of the Tosinvest Sanità group), in Rome (Italy), in particular focusing on its experience in the evaluation of upper limb movements in children affected by Cerebral Palsy.

Key words: upper limb, quantitative analysis of movement, kinematics, cerebral palsy, rehabilitation
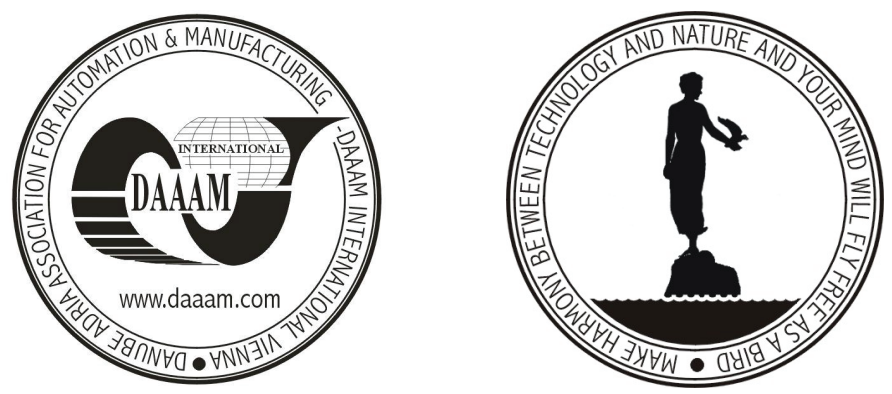

Authors' data: PhD. Student Cimolin V.[eronica]*, Ing. Galli M.[anuela]*, Prof. Dr. Crivellini M[arcello]*, Prof. Dr. Albertini G[iorgio]**, *Politecnico di Milano, Milano, Italy, **IRCCS "San Raffaele"-Tosinvest Sanità, Via della Pisana 235, Rome, Italy, veronica.cimolin@polimi.it, manuela.galli@polimi.it, marcello.crivellini@polimi.it, giorgio.albertini@sanraffaele.it

This Publication has to be referred as: Cimolin, V.; Galli, M.; Crivellini, M. \& Albertini, G. (2006). 3D-Kinematics of Upper Limb in Children with Cerebral Palsy: A Clinical Experience, Chapter 16 in DAAAM International Scientific Book 2006, B. Katalinic (Ed.), Published by DAAAM International, ISBN 3-901509-47-X, ISSN 1726-9687, Vienna, Austria

DOI: $10.2507 /$ daaam.scibook.2006.16 